\title{
STRUCTURAL UNITS OF HUMAN 7S GAMMA GLOBULIN *
}

\author{
By EDWARD C. FRANKLIN with the technical assistance of FRANCES PRELLI \\ (From the Department of Medicine and the Rheumatic Diseases Study Group, New York Uni- \\ versity College of Medicine, New York, N. Y.)
}

(Submitted for publication May 24, 1960; accepted August 17, 1960)

A number of observers in the past (1-3) have successfully degraded rabbit and horse antibodies with various enzymes, thus producing fragments retaining antibody activity. More recently Porter $(4,5)$ has produced split products of rabbit $\gamma$-globulin by treatment with papain and cysteine, two of which retained antibody activity as measured by their ability to inhibit precipitation of the original antiserum with homologous antigen, while the third appeared to retain the greatest antigenic specificity. Karush (6) and Nisonoff, Woernley and Wissler $(7,8)$ working with antihapten antibodies have clearly shown that these fragments are univalent. Putnam, Hsiao and Tan (9), employing similar techniques, have been able to split human $\gamma$-globulin and myeloma proteins into two major chromatographically separable fractions with sedimentation coefficients of approximately $3.5 \mathrm{~S}$. A preliminary report of some physical, chemical and immunological properties of similar subunits from human $\gamma$-globulins and several human antibodies has been presented (10). In the present report, results are presented which indicate that following digestion of human $\gamma$-globulin there are produced at least three fragments differing from each other in chemical properties. The major part of the antibody activity against three different antigens was found to be associated with one of these fragments, while smaller amounts were present in a second, antigenically similar fragment. The third fragment contained virtually no antibody activity but had additional antigenic specificity.

\section{MATERIALS AND METHODS}

Human $\gamma$-globulin was obtained as Cohn fraction II (Lederle, Lot no. C576). Ultracentrifugal examination demonstrated that this preparation consisted of approximately 95 per cent $7 \mathrm{~S} \gamma$-globulin, and that it contained less than 5 per cent of molecules with $s$ rates of 9 to $11 \mathrm{~S}$ and no detectable amounts of 19S $\gamma$-globulin. For stud-

* Supported by the Arthritis and Rheumatism Foundation, and by the United States Public Hẹalth Service, Grants A-2594 and A-1431 (C2). ies of specific antibodies, $\boldsymbol{\gamma}$-globulins were also isolated by starch zone electrophoresis (11) from the serum of a patient who developed serum sickness following the injection of tetanus antitoxin, and by precipitation with 34 per cent saturated ammonium sulphate from the serum of a patient hyperimmunized with diphtheria toxoid.

Breakdown of $\boldsymbol{\gamma}$-globulin was carried out as described by Porter (5) in $\mathrm{pH} 7.0$ phosphate buffered saline, 0.01 $\mathrm{M}$ cysteine and $0.002 \mathrm{M}$ ethylenediamine tetraacetate (EDTA) (Versene), using $1 \mathrm{mg}$ twice recrystallized papain per $100 \mathrm{mg}$ protein. ${ }^{1}$ The breakdown was allowed to proceed at $37^{\circ} \mathrm{C}$ for 12 to 18 hours. The material was

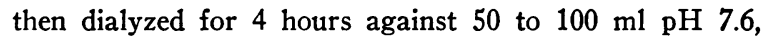
$0.01 \mathrm{M}$ phosphate buffer and then against $1 \mathrm{~L}$ of the same buffer for 24 hours. The amount of dialyzable material was determined by the modified Folin technique using $\gamma$-globulin as a standard (12). The exact nature of these products was not examined further. In a number of experiments, $3 \mathrm{mg}$ pepsin per $100 \mathrm{mg} \gamma$-globulin at $\mathrm{pH} 4$ was used, alone or in conjunction with subsequent treatment, with $0.1 \mathrm{M}$ mercaptoethanol as described by Nisonoff, Wissler and Woernley (8).

Ultracentrifugal analyses. Ultracentrifugal analyses were carried out in a Spinco Model E ultracentrifuge, using cells with a double sector centerpiece. Quantitative measurements were carried out directly from the photographic plates using a comparator (Gaertner) according to methods described by Trautman (13). Preparative ultracentrifugation was performed in a Spinco Model L ultracentrifuge, using a swinging bucket rotor (SW-39) and a saline gradient as described previously (14).

Chromatography. Chromatography was carried out on carboxymethylcellulose (CM cellulose) or Diethylaminoethylcellulose (DEAE cellulose) as described by Peterson and Sober (15).2 For preparative purposes glass columns, $2.5 \mathrm{~cm}$ OD and $40 \mathrm{~cm}$ long, were employed. Ten or $20 \mathrm{~g}$ of adsorbent was washed with distilled water and the starting buffer and packed into the column with approximately 10 pounds per square inch air pressure to a height of 15 and $30 \mathrm{~cm}$, respectively. The columns were equilibrated with a continuous flow of $2,000 \mathrm{ml}$ starting buffer. Two hundred fifty to $500 \mathrm{mg}$ of $\gamma$-globulin was dialyzed for 4 to 24 hours against the same buffer and carefully applied to the column. In the initial experiments, elution was carried out by gradient elution at con-

1 Prepared by Dr. J. Potter.

2 Purchased from Brown \& Co., New Hampshire: DEAE cellulose, Lot no. 1078, 1066, capacity $1 \mathrm{mEq}$ per g; CM cellulose, Lot no. 1100 , capacity $0.7 \mathrm{mEq}$ per $\mathrm{g}$. 
stant $\mathrm{pH}$ and increasing ionic strength, as described by Fahey and Horbett (16). The gradient was started after collection of the protein that came off with the solvent front. Since only a single additional peak was obtained from each column, subsequent studies were carried out by stepwise elution. Elution from the cation exchanger was carried out with $\mathrm{pH} 7.6$ phosphate buffer and from the anion exchanger at $\mathrm{pH}$ 8.0. Ionic strengths of 0.4 and 0.3 , respectively, were obtained by adding sodium chloride to $0.01 \mathrm{M}$ phosphate buffer. Ten-ml aliquots were collected with an automatic fraction collector, and protein was measured by reading the extinction in a Beckman DU spectrophotometer at $280 \mathrm{~m} \mu$. An approximation of the amount of protein in each tube was obtained by comparison with a standard curve prepared with Cohn fraction II $\gamma$-globulins. These values can be considered only as an approximation, since the amino acid composition of the fragments is not known.

Immunological and chemical studies. Immunological studies were carried out using a pooled antiserum to $7 \mathrm{~S}$ $\gamma$-globulin prepared in five rabbits over a prolonged period of immunization, and antisera to the whole unfractionated digested $\gamma$-globulin prepared in rabbits with Freund's adjuvant as previously described (17). Studies were carried out by double diffusion in agar by the technique of Ouchterlony (17), and by micro-immunoelectrophoresis by the technique of Scheidegger and Buzzi (18). Quantitative precipitin analyses were done as described previously (17) using 0.05 to $0.5 \mathrm{ml}$ antiserum.

Hexose was determined by the anthrone reaction (19) using a mixture of glucose, fucose and mannose as a standard, and hexosamine by a modification of the ElsonMorgan reaction using glucosamine as a standard (20). To calculate the hexose protein ratio of the fractions, protein was measured by the modified Folin technique using Cohn fraction II $\gamma$-globulin as a standard (12).

Antibody assays. 1) Precipitating antibody to horse serum proteins in electrophoretically isolated $\boldsymbol{\gamma}$-globulins from a patient with serum sickness was assayed by quan-
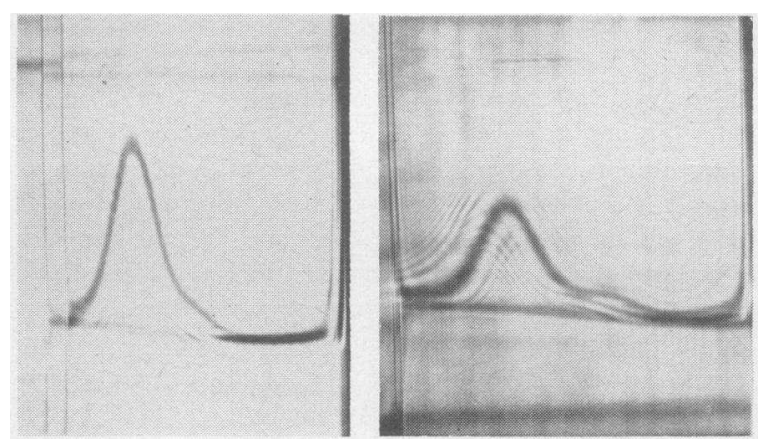

Fig. 1. Ultracentrifugal patterns of two prepaRATIONS OF DIGESTED $\gamma$-GLOBULIN SHOWING IN ADDITION TO THE MAJOR 3.5S PEAK, THE PRESENCE OF VARIABLE AMOUNTS OF A MORE RAPIDLy SEDIMENTING 5 TO 6S COMPONFNT; SPEED 52,640 RPM. Photographs taken after 64 minutes. Sedimentation proceeds from left to right. titative precipitin techniques (17). Inhibitory power of digested fragments was determined by quantitating their ability to decrease the amount of precipitate between the original antiserum and homologous antigen, and by their capacity to inhibit the passive cutaneous anaphylactic reaction when mixed with the antiserum injected into the skin of the guinea pig (21). ${ }^{3}$

2) Antibodies to diphtheria toxin in $\gamma$-globulins isolated from a hyperimmunized normal subject and in fragments prepared from them, were measured by their capacity to neutralize the effect of the toxin in the skin of a rabbit (22).4

3) Antibody to streptokinase was present in the preparation of Cohn fraction II, Lot no. 576, employed in these studies and was estimated by its ability to inhibit the activity of streptokinase using the fibrinolytic assay described by Johnson and Tillett (23). ${ }^{5}$

\section{RESULTS}

Treatment of 7S $\gamma$-globulin with papain, cysteine and EDTA, as described under Methods, resulted in virtually complete conversion of the starting material which had an observed $\mathrm{s}$ rate of 6.5 to $6.8 \mathrm{~S}$ into a major fraction with sedimentation coefficient of 3.4 to $3.5 \mathrm{~S}$ and small but variable amounts of more rapidly sedimenting material with a sedimentation coefficient of 5 to $6 \mathrm{~S}$. This sedimented somewhat more slowly than the starting material and probably represents partially degraded $\gamma$-globulin. Approximately 80 to 90 per cent of the total was not dialyzable, while the remaining 10 to 20 per cent appeared as dialyzable nitrogenous products. Two preparations of treated $\gamma$-globulin prepared from the same lot but showing different amounts of the more rapidly sedimenting material are shown in Figure 1.

When the digest was subjected to chromatography on a CM cellulose column at $\mathrm{pH} 7.6$ using a gradient of 0.01 to $0.4 \mathrm{M} \mathrm{NaCl}$, two major peaks were recovered. One of these came off with the starting buffer, and the second one shortly after the start of the gradient. Since this second peak could not be resolved further, subsequent experiments were carried out by stepwise elution using the starting buffer and $0.4 \mathrm{M} \mathrm{NaCl}, \mathrm{pH}$ 7.6. The results of one such experiment are shown in Figure 2 (top). The amounts of protein associated with each peak were quite variable; in general, peak I contained somewhat less protein than peak

${ }^{3}$ Kindly performed by Dr. Zoltan Ovary.

${ }^{4}$ Kindly performed by Dr. Jonathan Uhr.

"Kindly performed by Dr. Alan Johnson. 

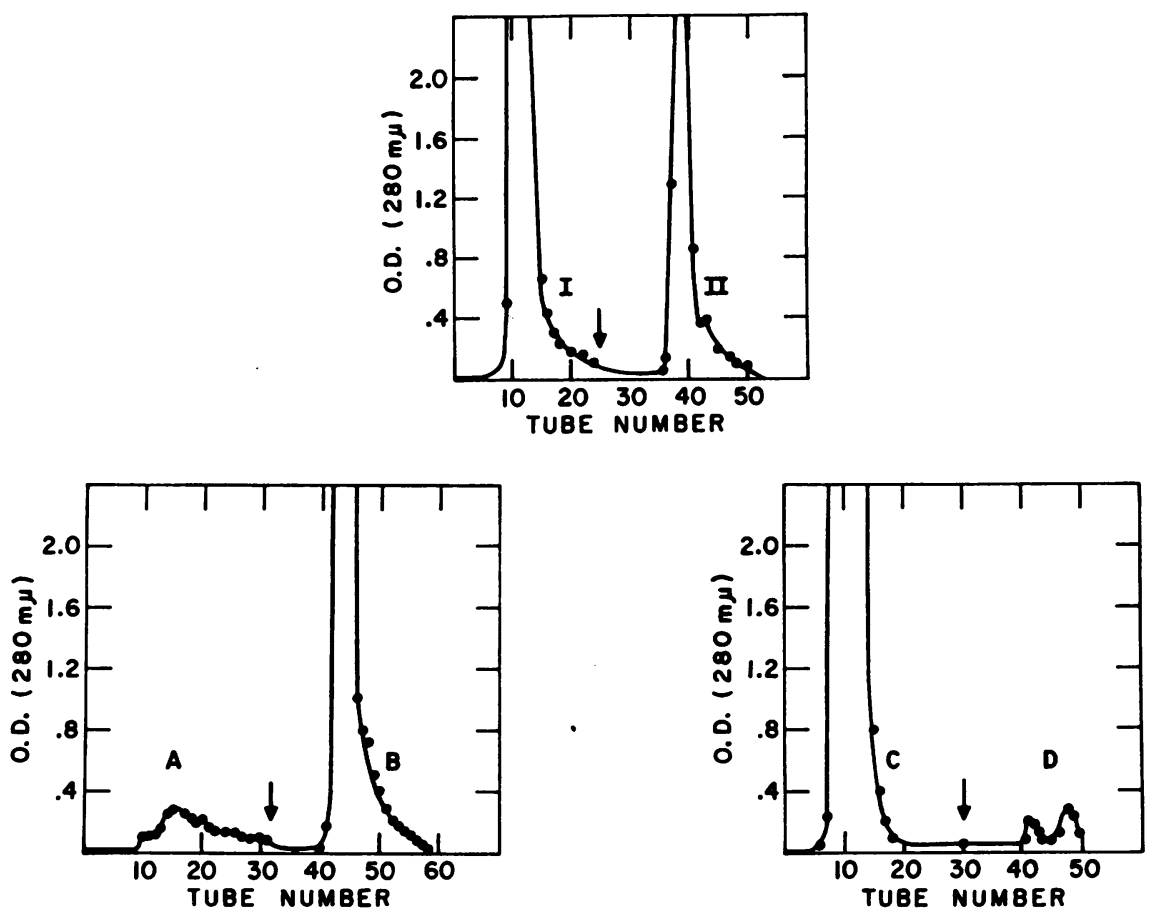

Fig. 2. Chromatography of digest of human $\gamma$-globulin. Top: first step on $\mathrm{CM}$ cellulose, $\mathrm{pH}$ 7.6. Arrow indicates change of eluting buffer. Bottom: rechromatography of peak I (left) and peak II (right) on DEAE cellulose, pH 8.0. Arrow indicates change of eluting buffer.

II. In some experiments, however, the reverse occurred. Rechromatography of each of the peaks revealed peak I to be quite pure. However, peak II frequently contained small amounts of contaminating protein and was therefore rechromatographed in a number of experiments before further separation was undertaken. While this step appeared to have resulted in appreciable resolution, immunological and chemical studies to be described below indicated that each fraction was still heterogeneous. Each fraction was therefore chromatographed further on a DEAE cellulose column at $\mathrm{pH} 8.0,0.01$ to $0.3 \mu$. By gradient elution each fraction could be further resolved into a major and one minor peak (IA and B) (IIC and D). Since in each instance only a single peak was recovered from the DEAE cellulose column after the starting buffer, subsequent experiments were again performed by stepwise elution with similar results. The peaks obtained in one such experiment are shown in Figure 2 (bottom). Rechromatography of each peak under identical conditions revealed only a single peak in the same position, thus indicating that these represent different mo- lecular species and not simply artifacts created during the fractionation procedure. The relative amounts of each fraction were variable. In general, fraction $\mathrm{C}$ was the largest single component and made up from 40 to 50 per cent of the total protein, while fraction A made up from 15 to 25 per cent of the total protein recovered. About one-quarter to one-third was recovered with fraction B. Fraction D rarely contained more than 5
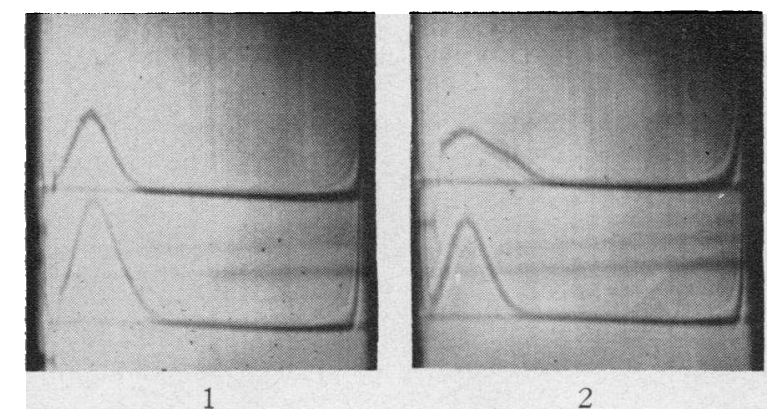

Fig. 3. Ultracentrifugal patterns. 1: Fraction A (top) and fraction B (bottom). 2: Fraction D (top) and fraction C (bottom). Speed 42,040 rpm. Photographs taken after 64 minutes. Sedimentation proceeds from left to right. 


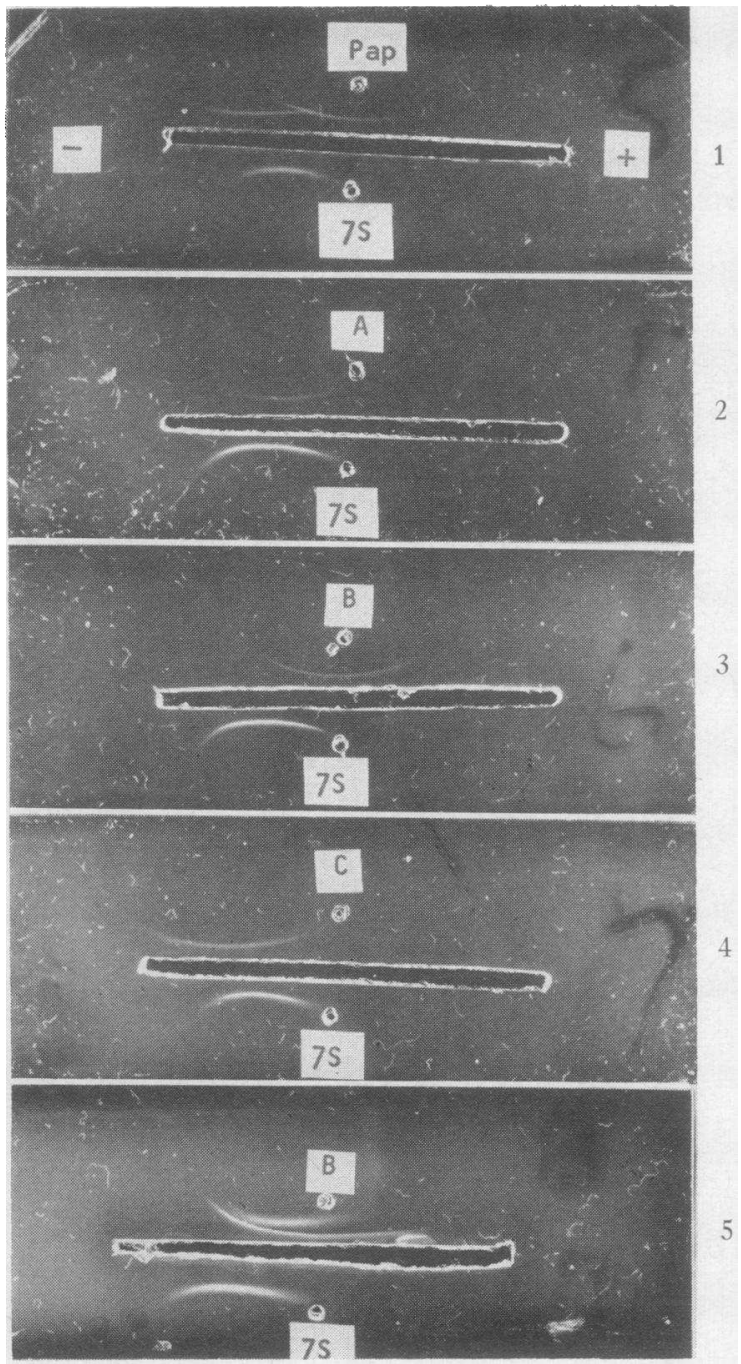

Fig. 4. ImMUNOELECTROPHORETIC PATterns COMPARING 7S $\gamma$-GLOBULIN ON THE BOTTOM OF EACH PATTERN WITH : 1) WHOLE PAPAIN DIGEST; 2) FRACTION A; 3) FRACTION B, 4) FRACTION C; AND 5) A SECOND PREPARATION OF FRACTION B. Anode is to the right.

per cent of the total. Total recovery of protein ranged from 85 to 95 per cent of the material applied.

Examination in the analytical ultracentrifuge demonstrated $\mathrm{A}, \mathrm{B}$ and $\mathrm{C}$ to sediment as single rather homogeneous peaks with an observed s rate of 3.4 to $3.5 \mathrm{~S}$ (Figure 3 ). D was heterogeneous and consisted of approximately equal amounts of two peaks with s rates of $3.5 \mathrm{~S}$ and 5 to $6 \mathrm{~S}$ (Figure $3)$. Molecular weights calculated by the Archibald technique were obtained for $\mathrm{A}, \mathrm{B}$ and $\mathrm{C}$ and ranged from 40,000 to 55,000 for each. Fraction D was too heterogencous for such analyses and was not examined further.

In view of the well recognized heterogeneity of $\gamma$-globulins and the lack of molar equivalence between these fractions, it was of interest to determine if they were derived from different fractions of $\gamma$-globulin. Chromatography of whole Cohn fraction II $\gamma$-globulin on CM cellulose at $\mathrm{pH} 7.6$ results in two major fractions. One of these is eluted with the starting buffer, is slightly less basic, and has a slightly more rapid electrophoretic mobility than the second one, which is eluted at higher salt concentration. When each of these fractions was separately digested with papain and chromatographed in a manner similar to that used for whole $\gamma$-globulin, both fractions yielded ap- proximately equal amounts of fraction B. However, they differed in the relative amounts of the two other peaks. The fraction eluted first yielded large amounts of fraction $\mathrm{A}$ and little $\mathrm{C}$, while the second one yielded larger amounts of fraction $\mathrm{C}$ and only small amounts of A. Small amounts of fraction $\mathrm{D}$ were obtained from both. Similarly when $\gamma$-globulin was fractionated into a slow moving and rapidly moving fraction by starch zone electrophoresis prior to digestion, relatively larger amounts of fraction $\mathrm{C}$ were isolated from the former, while the more rapidly migrating protein contained predominantly fraction $\mathrm{A}$. The relative amount of fraction B was approximately the same in both.

Antigenic properties. Figure 4 (top) compares the immunoelectrophoretic patterns obtained with $7 \mathrm{~S} \gamma$-globulin and the whole papain digest when they react with rabbit antiserum to $7 \mathrm{~S} \gamma$-globulin. While the native proteins gave only a single line, the papain digests formed two major lines which appeared to be independent of each other. One of these migrated more rapidly and the other more slowly than $\gamma$-globulin. Occasionally, a third line was also visible near the point of application. The four lower patterns in Figure 4 show similar studies with each of the separated fragments. Fragment $C$ corresponds to the major slow line of the whole digest, $\mathrm{B}$ to the major fast one, and $\mathrm{A}$ has an intermediate mobility but could not always be detected in the whole digest.

In a number of experiments fraction $B$ had a second line near the origin (Figure 4 , bottom). Fraction $D$ was heterogeneous and contained each 
of the lines present in the whole digest and was therefore not studied further. While fractions A and $C$ differed from each other in mobility, no distinct differences could be detected between them by double diffusion according to the method of Ouchterlony. Figure 5 compares the reaction of each fraction and 7S $\gamma$-globulin with a rabbit antiserum to $7 \mathrm{~S} \gamma$-globulin. It can be seen that the single major lines produced by fractions $\mathrm{A}$ and $\mathrm{C}$ fused with each other to give a reaction of identity (Figure 5B) but were antigenically deficient when compared to the native protein (Figure 5A). Occasionally a second faint outer line was visible (Figure 5A) which probably represented traces of contaminating material. Fraction $\mathrm{B}$ contained two major components which together appeared to have all of the constituents of the native protein (Figure 5A). Figure 5B demonstrates that one of the lines in fraction $B$ is antigenically distinct from $\mathrm{A}$ and $\mathrm{C}$ and crossed through them, while the second one appeared to be similar to them. Both lines in fraction B appear to be of the $3.5 \mathrm{~S}$ class and not due to undegraded 7S $\gamma$-globu-

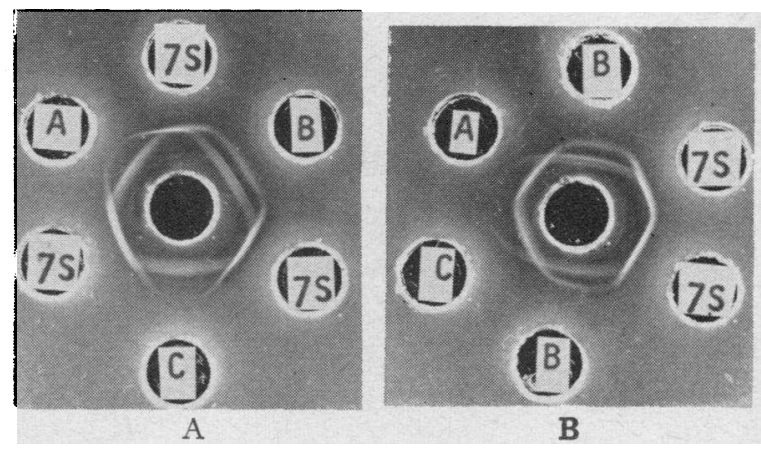

Fig. 5. OUChTERLONy dOUBle diffusion Plates COMPARING THE FRAGMENTS: A) WITH 7S $\gamma$-GLOBULIN; B) WITH EACH OTHER, USING AN ANTISERUM TO $7 \mathrm{~S} \gamma$-GLOBULIN IN THE CENTER WELL.

lin, since they were recovered in the top three fractions obtained by density gradient ultracentrifugation. Only a small portion of 7S $\gamma$-globulin, simultaneously separated in another tube, was found at this level.

Differences between these fractions and native 7S $\gamma$-globulin are also demonstrated by precipitin analyses shown in Figure 6 . None of the frag-

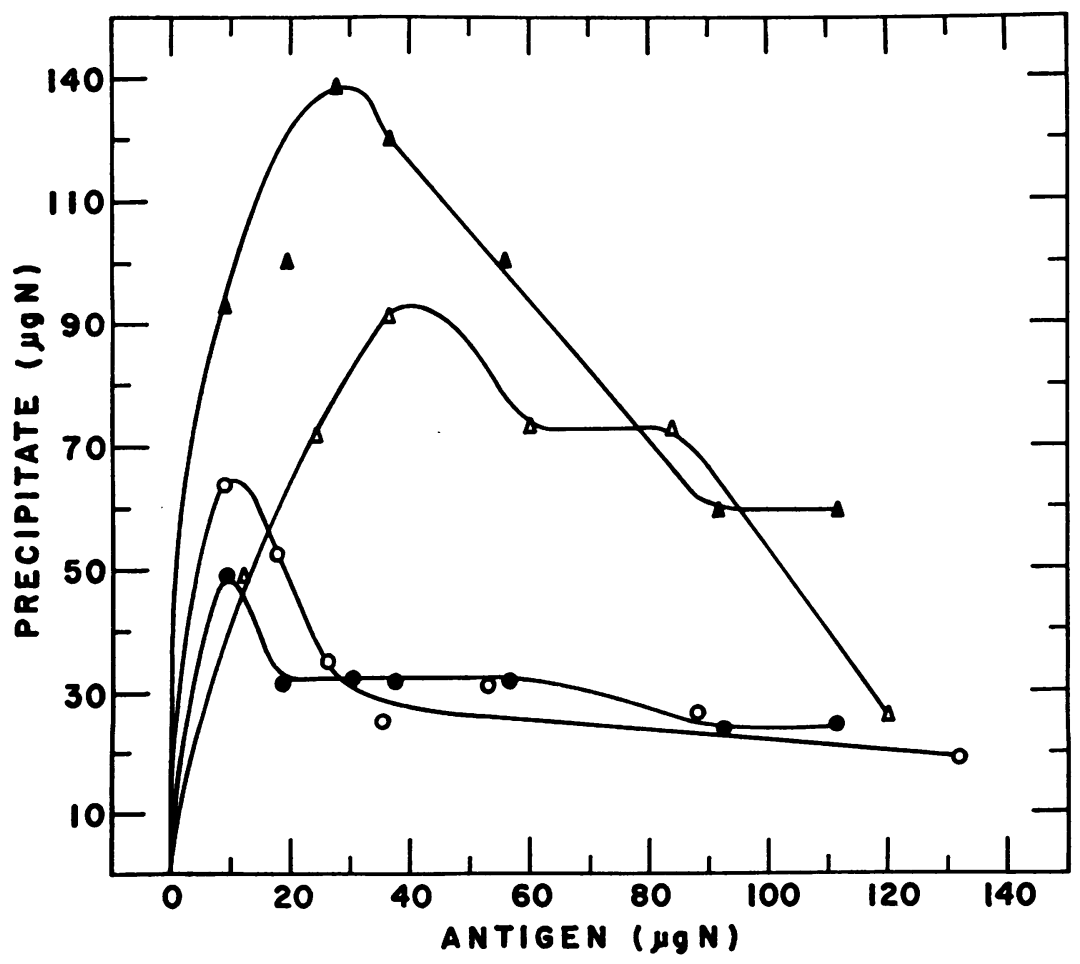

Fig. 6. Precipitin analyses comparing the Reactions of Fraction A

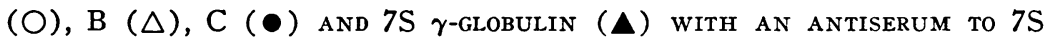
$\gamma$-GLOBULIN. 
TABLE I

The effect of the papain-digested fragments from antibodies to horse serum proteins on the precipitation of horse serum by the untreated antiserum

\begin{tabular}{lccc}
\hline \hline & & $\begin{array}{c}\text { Horse } \\
\text { serum- } \\
\text { human } \\
\text { antiserum }\end{array}$ & $\begin{array}{c}\text { Human } \\
\text { albumin- } \\
\text { rabbit } \\
\text { antiserum }\end{array}$ \\
\hline Fraction & $m g$ & $\mu g p p t$ & $\mu g p p t$ \\
None & & 88.0 & 475 \\
Papain digest & 1.28 & 14.0 & 480 \\
A & 1.25 & 42.5 & 475 \\
C & 1.36 & 10.5 & 475 \\
D & 0.50 & 57.0 & $*$
\end{tabular}

* Not determined.

ments precipitated as much antibody as did the original antigen. Supernatant analyses with 7S $\gamma$-globulins in antigen excess revealed complete neutralization of antibody by $7 \mathrm{~S} \gamma$-globulin, but residual activity against $7 \mathrm{~S} \gamma$-globulin remained in the region of antigen excess of fractions $\mathrm{A}$ and C.

Preliminary studies with antisera to the whole papain digest offered less resolution and little additional information.

Antibody analyses. Antibody activity of three human antibodies was tested following breakdown. Only one, an antiserum to horse serum, was a precipitating antibody under the conditions of the study. Following breakdown to $3.5 \mathrm{~S}$ fractions this antibody no longer precipitated with antigen, nor did any of the separated fragments. However, the whole papain digest inhibited the precipitation of the original antiserum and of the homologous antigen almost completely (Table I). When each of the isolated fractions was tested, fraction $C$ had most of the inhibitory activity, while A was less active at the same concentration. This particular experiment yielded amounts of

TABLE II

Antibody activity of papain-digested fragments prepared from diphtheria antitoxin and antistreptokinase

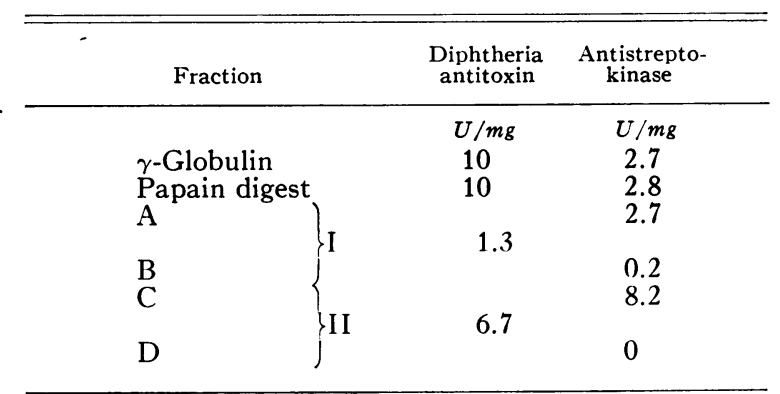

fraction $B$ too small for assay. Table I also indicates that none of the fractions had any effect on a heterologous system of human albumin and a rabbit antiserum. Similar results to be reported in detail separately were obtained by studying the inhibition by these fractions of passive cutaneous anaphylaxis, employing the antiserum and horse serum (24). Here, too, fraction $C$ and the whole papain digest were active. Fraction $\mathrm{D}$ did not inhibit, while fraction A had a nonspecific hemorrhagic and inhibitory effect on the homologous as well as on the heterologous antigen-antibody reaction.

Activity of the fractions produced from the other two antibodies was measured by their ability to neutralize toxin. In the case of diphtheria antitoxin, the rabbit skin assay was employed (22); for antibody to streptokinase the kinase inhibition

TABLE III

Carbohydrate composition of papain-digested fragments of Cohn fraction II $\gamma$-globulin

\begin{tabular}{|c|c|c|c|c|}
\hline \multirow{2}{*}{$\begin{array}{l}\gamma \text {-Globulin } \\
\text { Paprain diges } \\
\text { Fraction }\end{array}$} & \multicolumn{2}{|c|}{$\begin{array}{c}\text { Per cent } \\
\text { hexose } \\
1.2 \\
1.2\end{array}$} & \multicolumn{2}{|c|}{$\begin{array}{c}\text { Per cent } \\
\text { hexosamine } \\
1.0 \\
1.1\end{array}$} \\
\hline & Prep. 1 & Prei). 2 & Prep. 1 & Prep. 2 \\
\hline$A$ & 1.0 & 1.4 & 0.7 & 0.6 \\
\hline B & 3.0 & 3.1 & 1.7 & 2.0 \\
\hline $\mathrm{C}$ & 0.2 & 0.3 & 0.3 & 0.4 \\
\hline
\end{tabular}

was measured (23). Only $15 \mathrm{mg}$ of antidiphtheria $\gamma$-globulin was available and fractionation was not carried out beyond the first step of chromatography on CM cellulose. The results of these studies are listed in Table II. In each case the papain digest retained virtually all of the original activity. Following fractionation the bulk of activity was associated with the second peak eluted from the cation exchanger (peak II) in the case of diphtheria antitoxin, and with fraction $\mathrm{C}$ for streptokinase. In each instance, as in the case of the antibody to horse serum, about 15 to 25 per cent of the total activity was also associated with fractions I and A, respectively. ${ }^{6}$ The significance of this will be discussed below.

Carbohydrate analyses. In view of previous reports on the isolation of small glycopeptides from

${ }^{6}$ Qualitatively similar results have recently been obtained with another precipitating antibody than that to thyroglobulin. 
$\gamma$-globulin (25), it seemed of interest to determine the carbohydrate content of fractions prepared from Cohn fraction II. Table III indicates that digestion did not result in significant loss of carbohydrate. Following chromatography, fraction II and subfractions $C$ and D contained virtually no hexose or hexosamine; the bulk of the carbohydrate was associated with fraction I. Although results were variable, probably because of the presence of small degrees of impurities in each fraction, fraction $\mathrm{B}$ contained the largest amount of carbohydrate and approximately 3 per cent hexose and 2 per cent hexosamine, while A had somewhat lower values. The results of two representative experiments are listed in Table III. The first preparation represents fractions that had been rechromatographed on DEAE cellulose prior to analysis; the second preparation had been refractionated on CM cellulose. Thus, more than 75 per cent of the total hexose and hexosamine recovered in this preparation was associated with fraction $B$.

\section{DISCUSSION}

Normal human 7S $\gamma$-globulin has a molecular weight of approximately 160,000 and has been shown to consist of at least two peptide chains on the basis of careful end group analyses $(26,27)$. Detailed structural studies have been hampered not only by the large size and complex structure of the $\gamma$-globulin molecules, but also by the heterogeneity of $\gamma$-globulin (which should be called $\gamma$-globulins). Similar difficulties have also been encountered in the study of antibodies produced in other species. Thus, the basic question, whether antibodies to different antigens differ in their amino acid composition and primary structure, or whether antibody specificity is due to changes in the secondary structure of preformed $\gamma$-globulin molecules resulting from contact with the antigen, has not been answered. Previous studies, especially those of Kabat (28), have indicated, however, that the antibody combining sites are small, and carbohydrate analyses by Rosevear and Smith (25) indicate that the carbohydrate is associated with certain specific areas of the molecule. The recent observation of Porter (5) that rabbit $\gamma$-globulin can be reproducibly broken down into easily separable fragments with molecular weights of 50,000 to 80,000 suggested that similar studies of human $\gamma$-globulins and antibodies might provide some answers to these basic questions and facilitate further structural analyses of the $\gamma$-globulin molecule.

The results of the present study indicate that human $\gamma$-globulin can also be broken down into fragments having one-fourth to one-third the size of the original molecule. However, careful analyses of some of these units reveal certain differences which suggest a structure for human $\gamma$-globulin which differs from that of rabbit $\gamma$-globulin. The fragments so produced can be separated by chromatography into three major components differing in chemical and electrophoretic properties and, to some extent, antigenically. The fragment with the most rapid electrophoretic mobility and an additional antigenic component did not contain significant antibody activity, but contained more than three-quarters of the carbohydrate present in the original molecule. Most of the antibody activity was associated with the fraction with the least negative charge on immunoelectrophoresis (fraction C) which contained little carbohydrate; however, significant antibody activity was also associated with the fragment that was antigenically closely related to the latter (fraction A) but contained more carbohydrate and had a somewhat greater negative charge. The presence in $\gamma$-globulins of an antigenically distinct $\mathrm{F}$ component and of several antigenically closely related $\mathrm{S}$ and mid-components, which contribute to the electrophoretic mobility of the $\gamma$-globulins, has also recently been described by Edelman, Heremans, Heremans and Kunkel (29) in a study of the double line phenomenon. Studies with Cohn fraction II $\gamma$-globulin containing antibody to streptokinase indicate that it consists of two major fractions which can be separated by chromatography. These fractions differ somewhat in electrophoretic mobility and carbohydrate content, but resemble each other in having approximately similar amounts of antibody activity to streptokinase. Both fractions contain a common non-antibody fragment (fraction $\mathrm{B}$ ) which is rich in carbohydrate and makes up about one-fourth to one-third of the molecule. Some of their differences appear to be due to the presence of larger amounts of the more basic fragment $\mathrm{C}$ in the $\gamma$-globulin with the least negative charge and slower electrophoretic mobility, while greater amounts of the 
more rapidly migrating fragment $\mathrm{A}$ were recovered following digestion of the fraction of native $\gamma$-globulin with the higher electrophoretic mobility. It would thus appear that the electrophoretic mobility of the native protein is partially determined by the relative amounts of those fragments which also have the antibody combining sites.

The chemical analyses are consistent with previous reports on the association of carbohydrate with certain low molecular weight peptides with molecular weights of less than 5,000 (25). Of particular interest in these studies is the demonstration of the existence of at least two distinct antigenic fragments. While comparison of these with native $\gamma$-globulin suggests neither loss nor release of antigenic groups present in the native molecule, preliminary studies, comparing them to fragments produced by treatment with pepsin and mercaptoethanol as described by Nisonoff and associates (8), suggest the possible loss of a few antigenic groups present in the native protein following digestion with papain.

The exact nature of the bonds holding the fragments together cannot be determined with certainty from these studies. However, the observations that a number of closely related smaller fragments can be prepared from rabbit and human $\gamma$-globulins by sulfhydryl reagents combined with denaturing agents $(30)$, papain $(4,5)$ or pepsin (8) suggest that the common mechanism may be the reduction of disulfide bonds by the sulfhydryl reagent, and that the enzyme or denaturing agent may make these accessible by unfolding the molecule or by breaking off a fragment. While the close similarity of the antigenic properties of fractions $\mathrm{A}$ and $\mathrm{C}$ when tested with rabbit antisera raises the possibility that they are identical, such a view does not appear likely, since they differ in some of their chemical properties, in electrophoretic mobility, and in antigenicity when tested with antisera produced in different species (31). Furthermore, the differences in the composition of $\gamma$-globulins fractionated by several techniques prior to digestion, suggest that $\gamma$-globulins consist of a heterogeneous group of proteins differing in the relative amounts of these fractions. It is of interest that a small fraction (about 5 per cent) of the $\gamma$-globulin resists breakdown to the $3.5 \mathrm{~S}$ units.

The production of $3.5 \mathrm{~S}$ units and of nonprecipi- tating fragments is not only of theoretical interest in elucidating the structure of $\gamma$-globulin, but may eventually shed light on the synthesis and specificity of antibody structure. In addition, such nonprecipitating fragments with antibody activity may prove of use in neutralizing certain noxious antigens without the danger of producing tissue damage caused by the interaction of antigen with antibody fixed to tissues. Ovary and Karush (21) have shown that antibody-containing fragments of rabbit $\gamma$-globulins do not fix to the skin and, therefore, presumably not to other tissues. Similarly, none of the human fragments appears to fix to the skin as measured by reverse passive cutaneous anaphylaxis (31). This observation would suggest that such univalent fragments may be of use in neutralizing circulating noxious antigens without the production of tissue damage before they can elicit an antibody response by the host. Similarly, the role of these fragments in the fixation of complement and other immune mechanisms, and the relationship of these artificial fragments to those produced in vivo (32) remain to be explored.

\section{SUMMARY}

1. Breakdown of human $7 \mathrm{~S} \gamma$-globulin with papain and cysteine results in three major chromatographically separable fractions with sedimentation coefficients of 3.4 to $3.5 \mathrm{~S}$, molecular weights of 40,000 to 55,000 , and small amounts of partially degraded $\gamma$-globulin.

2. Each of these is antigenically related to the native protein. Two of these ( $A$ and $C$ ) are closely related to each other but differ in electrophoretic mobility, while the third one (B) differs from them also antigenically.

3. Most of the carbohydrate is associated with fraction $\mathrm{B}$; more than three-fourths of the antibody activity against three different antigens is found in fraction $\mathrm{C}$, with small amounts in fraction $\mathrm{A}$.

4. The role of these structural units in determining some of the known properties of $\gamma$-globulins is discussed.

\section{REFERENCES}

1. Petermann, M. L., and Pappenheimer, A. M., Jr. The ultracentrifugal analysis of diphtheria proteins. J. phys. Chem. 1941, 45, 1. 
2. Porter, R. R. The formation of a specific inhibitor by hydrolysis of rabbit antiovalbumin. Biochem. J. 1950, 46, 479.

3. Grabar, P. Sur l'action de la pepsine sur les anticorps antipneumococciques. C. R. Acad. Sci. (Paris) 1938, 207, 807.

4. Porter, R. R. Separation and isolation of fractions of rabbit gamma-globulin containing the antibody and antigenic combining sites. Nature (Lond.) 1958, 182, 670 .

5. Porter, R. R. The hydrolysis of rabbit $\gamma$-globulin and antibodies with crystalline papain. Biochem. J. 1959, 73, 119.

6. Karush, F. Properties of papain-digested purified antihapten antibody. Fed. Proc. 1959, 18, 577.

7. Nisonoff, A., and Woernley, D. L. Effect of hydrolysis by papain on the combining sites of an antibody. Nature (Lond.) 1959, 183, 1325.

8. Nisonoff, A., Wissler, F. C., and Woernley, D. L. Mechanism of formation of univalent fragments of rabbit antibody. Biochem. biophys. Res. Com. 1959, 1, 318.

9. Putnam, F. W., Hsiao, S.-h., and Tan, M. Papain cleavage of human and rabbit $\gamma$-globulins. Fed. Proc. 1960, 19, 77.

10. Franklin, E. C. Some properties of the breakdown products of human $7 \mathrm{~S}$ gamma globulin and antibodies (abstract). J. clin. Invest. 1960, 39, 986.

11. Kunkel, H. G. Zone electrophoresis in Methods of Biochemical Analysis, D. Glick, Ed. New York, Interscience Publishers, 1954, vol. 1, p. 141.

12. Lowry, O. H., Rosebrough, N. J., Farr, A. L., and Randall, R. S. Protein measurement with Folin phenol reagent. J. biol. Chem. 1951, 193, 265.

13. Trautman, R. Operating and comparating procedures facilitating Schlieren pattern analysis in analytical ultracentrifugation. J. phys. Chem. 1956, 60, 1211.

14. Kunkel, H. G., Franklin, E. C., and Muller-Eberhard, H. J. Studies on the isolation and characterization of the "rheumatoid factor." J. clin. Invest. 1959, 38, 424.

15. Peterson, E. A., and Sober, H. A. Chromatography of proteins. I. Cellulose ion-exchange adsorbents. J. Amer. chem. Soc. 1956, 78, 751.

16. Fahey, J. L., and Horbett, A. P. Human gamma globulin fractionation on anion exchange cellulose columns. J. biol. Chem. 1959, 234, 2645.

17. Franklin, E. C., and Kunkel, H. G. Immunologic differences between the $19 \mathrm{~S}$ and $7 \mathrm{~S}$ components of normal human $\gamma$-globulin. J. Immunol. 1957, 78, 11.

18. Scheidegger, J. J., and Buzzi, C. Etude immunoélectrophorétique des gamma-globulines: Identification de plusieurs déterminants antigéniques grâce au protéines de Bence-Jones et aux sérums de myélomes. Rev. franc. Et. clin. biol. 1957, 2, 895.

19. Mokrasch, L. C. Analysis of hexose phosphates and sugar mixtures with the anthrone reagent. J. biol. Chem. 1954, 208, 55.

20. Elson, L. A., and Morgan, W. T. J. A colorimetric method for the determination of glucosamine and chondrosamine. Biochem. J. 1933, 27, 1824.

21. Ovary, Z., and Karush, F. Personal communication.

22. Fraser, D. T. The technic of a method for the quantitative determination of diphtheria antitoxin by a skin test in rabbits. Trans. roy. Soc. Can. 1931, 25, sect. V, 175.

23. Johnson, A. J., and Tillett, W. S. The lysis in rabbits of intravascular blood clots by the streptococcal fibrinolytic system (streptokinase). J. exp. Med. 1952, 95, 449.

24. Ovary, Z. Immediate reactions in the skin of experimental animals provoked by antigen antibody interaction in Progress in Allergy, P. Kallos, Ed. Basel, Karger, 1958, p. 459.

25. Rosevear, J. W., and Smith, E. L. Structure of glycopeptides from human $\gamma$-globulin. J. Amer. chem. Soc. 1958, 80, 250.

26. Putnam, F. W. N-terminal groups of normal human gamma globulin and of myeloma proteins. J. Amer. chem. Soc. 1953, 75, 2785.

27. McFadden, M. L., and Smith, E. C. The free amino groups of $\gamma$-globulins of different species. J. Amer. chem. Soc. 1953, 75, 2784.

28. Kabat, E. A. The upper limit for the size of the human antidextran combining site. J. Immunol. 1960, 84, 82.

29. Edelman, G. M., Heremans, J. F., Heremans, M. T., and Kunkel, H. G. Immunological studies of human $\gamma$-globulin. Relation of the precipitin lines of whole $\gamma$-globulin to those of the fragments produced by papain. J. exp. Med. 1960, 112, 203.

30. Edelman, G. M. Dissociation of $\gamma$-globulin. J. Amer. chem. Soc. 1959, 81, 3155.

31. Ovary, Z., and Franklin, E. C. To be published.

32. Franklin, E. C. Physicochemical and immunologic studies of gamma globulins of normal human urine. J. clin. Invest. 1959, 38, 2159. 